\title{
Influence of Light Quality and Intensity on Biomass and Biochemical Contents of Hydroponically Grown Lettuce
}

\author{
Kui Lin \\ College of Horticulture, Fujian Agriculture and Forestry University, Fuzhou \\ 350002, China; and Center of Excellence for Research in Optoelectronic \\ Agriculture, Fujian Agriculture and Forestry University, Fuzhou 350002, \\ China
}

\section{Zhi Huang \\ College of Horticulture, Fujian Agriculture and Forestry University, Fuzhou 350002, China \\ Yong $\mathrm{Xu}^{1}$ \\ Center of Excellence for Research in Optoelectronic Agriculture, Fujian Agriculture and Forestry University, Fuzhou 350002, China}

Additional index words. photomorphogenesis, chlorophyll, green light, light-emitting diode (LED), Lactuca sativa

\begin{abstract}
The effects of different light intensities and qualities on the biomass, physiological parameters, and biochemical contents of hydroponically grown lettuce (Lactuca sativa L.) were evaluated, with the aim of obtaining better quality and higher yield, as well as saving energy in lettuce cultivation. Three different light qualities, provided by red (R), green (G), and blue (B) light-emitting diodes (LEDs), were used to produce six different combinations of illumination: $A 1: R: G: B=7: 0: 3$ [photosynthetic photon flux density (PPFD) $\left.=150 \mu \mathrm{mol} \cdot \mathrm{m}^{-2} \cdot \mathrm{s}^{-1}\right]$; A2: R:G:B $=6: 2: 2\left(150 \mu \mathrm{mol} \cdot \mathrm{m}^{-2} \cdot \mathrm{s}^{-1}\right)$ A3: R:G:B = 7:0:3 (120 $\left.\mu \mathrm{mol} \cdot \mathrm{m}^{-2} \cdot \mathrm{s}^{-1}\right)$; B1: R:G:B = 3:0:7 (150 $\left.\mu \mathrm{mol} \cdot \mathrm{m}^{-2} \cdot \mathrm{s}^{-1}\right)$; B2: R:G: $B=2: 2: 6\left(150 \mu \mathrm{mol} \cdot \mathrm{m}^{-2} \cdot \mathrm{s}^{-1}\right)$; and B3: R:G:B = 3:0:7 $\left(120 \mu \mathrm{mol} \cdot \mathrm{m}^{-2} \cdot \mathrm{s}^{-1}\right)$, and the fluorescent lamp (FL) at $150 \mu \mathrm{mol} \cdot \mathrm{m}^{-2} \cdot \mathrm{s}^{-1}$ was used as the control (CK). In most cases, treatment $\mathrm{A} 2$ resulted in higher biomass attributes, whereas higher physiological parameters were observed in treatment B2. However, a greater shoot dry weight (SDW) was observed in treatment A1. No significant difference was detected in chlorophyll $[\mathrm{Chl}(a+b)]$ and carotenoid (CAR) contents among the different treatments. Soluble sugar content was found the highest in treatment A1, although it was not significant compared with that observed in treatment A2. Soluble protein content was higher in treatments with a higher component of blue light. Vitamin $C$ content was found the highest in treatment $B 3$ and the lowest in treatment A1, whereas malondialdehyde (MDA) content was the highest in $\mathrm{CK}$ and the lowest in treatments B1 and B2. These results indicated that appropriate ratio of red to blue light can effectively promote the accumulation of biochemical compounds in lettuce and that replacement of a certain portion of red light, blue light, or both with green light was more effective in promoting plant growth and quality.
\end{abstract}

Light is one of the fundamental environmental factors affecting plant growth and development, as well as the biosynthesis and accumulation of biochemical compounds (Jeong et al., 2012; Kopsell and Kopsell, 2008; Pérez-Balibrea et al., 2008). This can be effectively demonstrated by using various wavelengths to regulate plant growth patterns. For example, red light plays a significant role in photosynthetic reactions and the transport of assimilates (Baroli et al., 2008),

\footnotetext{
Received for publication 19 Dec. 2018. Accepted for publication 22 Mar. 2018.

This research was supported by the Agriculture "Five Innovations" Project of the Development and Reform Commission of Fujian Province (K6015004).

${ }^{1}$ Corresponding author. E-mail: y.xu@fafu.edu.cn.
}

to best meet the requirements of plant growth and development. Hence, they have been widely used in plant factories and as supplemental lightings in greenhouses.

One of the most widely investigated vegetables using artificial lights is lettuce (L. sativa L.), which is a leafy vegetable that provides a source of essential vitamins, minerals, and protein and has been reported to be beneficial in reducing the risk of heart disease and cancer and promoting antiaging and other health-related functions (Lee et al., 2009; Nicolle et al., 2004; Park et al., 2008; Zao et al., 2004). In recent years, it has become one of the main vegetable species grown under soilless facility cultivation. Varying effects of light quality on the biomass, physiology, and biochemical contents of lettuce have been reported. Blue light, e.g., promotes the growth of lettuce plants (Johkan et al., 2010) and also increases Chl content and total phenolic and flavonoid concentrations (Son and Oh, 2013), whereas lettuce illuminated with red light shows comparably higher SDW (Kobayashi et al., 2013) and leaf area (Wu et al., 2007). A combination of red and blue light has also been proven to enhance the growth and biomass of lettuce grown in a controlled environment (Yorio et al., 2001). Nevertheless, conflicting results have been obtained in previous studies regarding the effects of green light on lettuce growth. Some have shown that the presence of green light in LED sources might repress lettuce growth (Klein et al., 1965; Song et al., 1997), whereas others have found that green light enhances the growth of lettuce (Kim et al., 2004) and Hibiscus syriacus (Huh et al., 1997). However, these studies did not provide information on the central wavelength and spectrum distribution of light sources, which made it difficult for other researchers to repeat these experiments. It is therefore important for researchers to clearly describe the exact distribution of light sources when applying LEDs in plant lighting, so that the effect of different wavelengths on plant growth can be easily identified. Although previous studies have added green light to combinations of red and blue LEDs, little information is available in the literature regarding the effects of green light on the physiological and biochemical characteristics of plants. Moreover, we were unable to find any information in the literature concerning the relative influence of the same amount of green light and other lights on plants. Previous studies have shown that, within a certain range, increasing light intensity can promote the growth and biochemical characteristics of lettuce (Fu et al., 2012; Kang et al., 2013; Li and Kubota, 2009). In this regard, we adopted a slightly different approach in the present study. We investigated the effects of green light as a replacement to part of the red LED, blue LED, or both on the growth and development of lettuce to investigate whether it is necessary to supply green light in a plant factory and whether the effect of the same amount of green light on plants is similar to that of the 
other light sources. Our purpose was to obtain better quality and higher yield, as well as to identify energy-saving measures in the cultivation of lettuce by using different combinations of red, green, and blue lights. The results obtained in this study showed that appropriate ratios of red to blue light could effectively promote the accumulation of biochemical compounds and that replacement of a certain portion of red light, blue light, or both with green light was more effective in promoting plant growth and quality.

\section{Materials and Methods}

Plant material and culture conditions. The leaf lettuce (L. sativa L.) "Korea" used in this study was provided by Yong Rong Seeds Ltd., Fuzhou, China. Healthy plump seeds were selected and soaked in warm water at 25 to $30{ }^{\circ} \mathrm{C}$ for $8 \mathrm{~h}$. Thereafter, the seeds were air-dried and then incubated at $18{ }^{\circ} \mathrm{C}$ for $1-2 \mathrm{~d}$ to accelerate germination. Germinated seeds were sown in plug trays $(510 \times$ $280 \times 50 \mathrm{~mm}$ ) containing a nursery matrix consisting of peat, vermiculite, and perlite in a 3:1:1 ratio and then irrigated with tap water.

Seedlings grown to the three-leaf stage were transplanted to a closed chamber-type plant-cultivating shelf comprising four layers, each of which was divided into three chambers. The chambers were illuminated from above with model 5050 RGB linear LED light bars (Unihero Corporation, Shenzhen, China). The nutrient film technique was used to cultivate the seedlings, in which a nutrient solution was retained within a plastic foam board containing fixed holes. The composition of the nutrient solution was as follows: 0.67 $\mathrm{mmol} \cdot \mathrm{L}^{-1} \mathrm{NH}_{4}^{+}-\mathrm{N}, 7.33 \mathrm{mmol} \cdot \mathrm{L}^{-1} \mathrm{NO}_{3}{ }^{-} \mathrm{N}$, $0.74 \mathrm{mmol} \cdot \mathrm{L}^{-1} \mathrm{P}, 4.74 \mathrm{mmol} \cdot \mathrm{L}^{-1} \mathrm{~K}, 2$ $\mathrm{mmol} \cdot \mathrm{L}^{-1} \mathrm{Ca}, 1 \mathrm{mmol} \cdot \mathrm{L}^{-1} \mathrm{Mg}$, and 1.67 $\mathrm{mmol} \cdot \mathrm{L}^{-1} \mathrm{~S}$. After plants had been cultivated hydroponically for 3 weeks under conditions of $20 \pm 2{ }^{\circ} \mathrm{C}$ and $75 \% \pm 5 \%$ relative humidity, growth parameters and physiological and biochemical properties were measured according to a random sampling method. All measurements were repeated three times for the same sample.

Light treatments. Three light qualities, namely, red (R), green $(\mathrm{G})$, and blue (B), provided by LEDs at two intensities (PPFD of 120 or $150 \mu \mathrm{mol} \cdot \mathrm{m}^{-2} \cdot \mathrm{s}^{-1}$ ) were used to evaluate the effects of green light on the biomass, physiological parameters, and biochemical contents of hydroponically grown lettuce, and the FL at $150 \mu \mathrm{mol} \cdot \mathrm{m}^{-2} \cdot \mathrm{s}^{-1}$ was used as CK (Table 1). The peak wavelengths of R, G, and $\mathrm{B}$ lights are 658, 518, and $445 \mathrm{~nm}$, respectively, and the full width at half maximum of them is $22 \mathrm{~nm}$. Lighting for all treatments was set at a $16-\mathrm{h}$ photoperiod $(16 \mathrm{~h}$ light $/ 8 \mathrm{~h}$ dark) and the photosynthetic photon flux levels were measured at the top of the plant canopy ( $15 \mathrm{~cm}$ from the LED lamps) using a spectroradiometer (HR-350; Hipoint, Taiwan).

The rationale underlying the settings of the lighting schemes shown in Table 1 is described as follows.

Table 1. Light quality and intensities used in the study.

\begin{tabular}{|c|c|c|}
\hline & Light quality (light-emitting diode) & \\
\hline Treatment & Red:Green:Blue & Intensity $\left(\mu \mathrm{mol} \cdot \mathrm{m}^{-2} \cdot \mathrm{s}^{-1}\right)$ \\
\hline Fluorescent lamp (CK) & $2.6: 4.2: 3.1$ & 150 \\
\hline A1 & $7: 0: 3$ & 150 \\
\hline $\mathrm{A} 2$ & $6: 2: 2$ & 150 \\
\hline A3 & $7: 0: 3$ & 120 \\
\hline B1 & $3: 0: 7$ & 150 \\
\hline B2 & $2: 2: 6$ & 150 \\
\hline B3 & $3: 0: 7$ & 120 \\
\hline
\end{tabular}

1. The light composition in treatment A2 was obtained by replacing one portion of blue and one portion of red light in treatment A1 with green light, with the aim of investigating the influence of green light on the growth characteristics of lettuce and the relative importance of green light.

2. The light composition in treatment A3 was obtained by removing the green light from treatment $\mathrm{A} 2$, to investigate the influence of light on the growth characteristics of lettuce after green light had been removed.

3. The light compositions in treatments B1-B3 were designed based on the same principles as those in treatments A1-A3 with the intensities of red and blue lights reversed.

Measurement of growth parameters. The influence of various combinations of light on lettuce growth was evaluated using the following growth parameters: plant height (HP), hypocotyl diameter [(stem diameter (SD)], shoot fresh weight (SFW), root fresh weight (RFW), SDW, root dry weight (RDW), and hypocotyl length (HL). The water content (WC) in aerial parts was also determined. Measurement of HP was taken from the base of the rhizome to the top of the plant using a ruler. SD was measured at the nodes of the first leaf using a vernier caliper. SFW, SDW, RFW, and RDW were measured using an electronic analytical balance and HL was measured from the radicle to the cotyledon using a ruler. The $\mathrm{WC}$ in aerial parts was determined using the following equation:

Water content $(\mathrm{WC})=\frac{\mathrm{SFW}-\mathrm{SDW}}{\mathrm{SFW}} \times 100 \%$.

Measurement of Chl and CAR contents. We used a mixture extraction method to measure the content of photosynthetic pigments. Chl and CAR were extracted and eluted with $10 \mathrm{~mL}$ extraction solution [acetone/ethanol/water $(4.5 / 4.5 / 1, \mathrm{v} / \mathrm{v} / \mathrm{v})]$ from $0.2 \mathrm{~g}$ samples of fresh shoot. The extraction was performed overnight at room temperature until the color of the sample became white. The supernatant was filtered and made to a final volume of $25 \mathrm{~mL}$ by using the extraction solution. The absorbance of the supernatant was measured spectrophotometrically at wavelengths of 663,645 , and 440 nm (TU-1810; Purkinje, Beijing, China).
The concentrations of Chl $a$ and $b$ and CAR were determined according to Arnon (1949) and Wettstein (1957), respectively.

Determination of soluble sugars. Soluble sugar contents were determined using the method described by Wang (2006). Ten milliliters of water was added to $0.2 \mathrm{~g}$ fresh shoot samples, followed by mixing and heating to $100^{\circ} \mathrm{C}$ for $30 \mathrm{~min}$. The supernatant was collected and the volume made to $25 \mathrm{~mL}$. Soluble sugar content was recorded spectrophotometrically at a wavelength of $630 \mathrm{~nm}$ using the sulfuric acid-anthrone method.

Determination of soluble proteins. Soluble protein contents were measured using the method proposed by Bradford (1976). Fresh shoot samples $(1 \mathrm{~g})$ were ground in a mortar with $2 \mathrm{~mL}$ distilled water, and then the mortar was washed several times using $6 \mathrm{~mL}$ distilled water. The wash solutions were collected and transferred to the same centrifuge tube. The tube was left standing at room temperature for $1 \mathrm{~h}$ to facilitate complete extraction. Thereafter, the tube was centrifuged at $4000 \mathrm{r} / \mathrm{min}$ for $20 \mathrm{~min}$ at room temperature, and the supernatant was made up to a final volume of $10 \mathrm{~mL}$ with distilled water. A $0.1-\mathrm{mL}$ aliquot of this supernatant was added to $5 \mathrm{~mL}$ of Coomassie brilliant blue G-250 solution $\left(0.1 \mathrm{~g} \cdot \mathrm{L}^{-1}\right)$. After standing for $2 \mathrm{~min}$, the soluble protein content was determined at a wavelength of $595 \mathrm{~nm}$.

Determination of vitamin $C$. The vitamin C content of lettuce was measured using a xylene extraction colorimetric method (Wang, 2006). Samples of fresh shoot (2 g) were ground in a mortar with $3 \mathrm{~mL}$ of $2 \%$ oxalic acid and the residue was washed with $1 \%$ oxalic acid. To the resultant solution, $1 \mathrm{~mL}$ of $30 \%$ zinc sulfate and $1 \mathrm{~mL}$ of $15 \%$ potassium ferrocyanide were added, and the mixture was made up to a volume of $100 \mathrm{~mL}$ with $1 \%$ oxalic acid. The supernatant was transferred to a test tube, to which $2 \mathrm{~mL}$ dye (prepared using $100 \mathrm{mg}$ of 2, 6-dichlorophenol indophenol and $82 \mathrm{mg}$ sodium hydrogen carbonate) and $5 \mathrm{~mL}$ xylene were added and mixed. After $0.5 \mathrm{~min}$, the vitamin $\mathrm{C}$ content was determined spectrophotometrically (TU1810; Purkinje) by measuring the absorbance at a wavelength of $500 \mathrm{~nm}$.

Measurement of MDA content. The MDA content of lettuce was measured using the method of Du and Bramlage (1992). Briefly, $0.5 \mathrm{~g}$ samples of fresh shoot were added to $5 \mathrm{~mL}$ of $5 \%(\mathrm{w} / \mathrm{v})$ trichloroacetic acid and centrifuged at $3000 \mathrm{r} / \mathrm{min}$ for $10 \mathrm{~min}$ at room temperature. A 2-mL aliquot of the resulting supernatant was added to $2 \mathrm{~mL}$ of $0.67 \%$ 
$(\mathrm{w} / \mathrm{v})$ thiobarbituric acid in $10 \%(\mathrm{w} / \mathrm{v})$ trichloroacetic acid. The mixture was heated at $100{ }^{\circ} \mathrm{C}$ for $30 \mathrm{~min}$ and then left to cool. After centrifugation, the absorbance of the supernatant was recorded spectrophotometrically at wavelengths of 600,532 , and $450 \mathrm{~nm}$ to determine the MDA content.

Statistical analysis. Data were processed using data processing system v7.05 (Liu et al., 2013) and Excel software. Statistical analysis was conducted using one-way analysis of variance with mean comparisons performed using the least significant difference test at an $\alpha$ level of 0.05 . After determining the mean and standard error of each treatment, the software was used to draw the corresponding graphs, as well as to analyze whether there were significant differences among the different treatments.

\section{Results and Discussion}

Light quality and intensity are among the most important factors that affect plant growth, yield, and nutritional quality. In addition to their effects on flowering and morphogenesis, LEDs also promote the accumulation of functional chemicals in plants (Lin et al., 2013). Lettuce, which is a fastgrowing crop and one of the main vegetables grown in greenhouses worldwide, is sensitive to the quality and intensity of light (Dougher and Bugbee, 2001). In the present study, the biomass and physiological and biochemical attributes of lettuce were evaluated after cultivated under illumination with LED lights at different qualities and intensities. Table 2 shows the effect of different light quantities and qualities on the biomass and physiological parameters (Chl and CAR contents) of lettuce 3 weeks after transplanting. The effects of different light quantities and qualities on the content of soluble sugars, soluble proteins, vitamin $\mathrm{C}$, and MDA in lettuce are shown in Fig. 1. On the basis of these results, we can deduce the following features.

Influence of light intensity on the biomass and biochemical contents of lettuce. Treatments $\mathrm{A} 1$ and $\mathrm{A} 3$ and $\mathrm{B} 1$ and $\mathrm{B} 3$ had the same light qualities, respectively, whereas treatments A3 and B3 had lower light intensities. Comparing these two pairs of treatments, we found that the biomass of lettuce shoots was significantly affected by light intensity. Most of the important biomass parameters, including HP, SD, SFW, and SDW, were higher in $\mathrm{A} 1$ and $\mathrm{B} 1$ than in $\mathrm{A} 3$ and $\mathrm{B} 3$, respectively. By contrast, other parameters, including RFW, RDW, and $\mathrm{WC}$, were lower in $\mathrm{A} 1$ and $\mathrm{B} 1$ than in $\mathrm{A} 3$ and $\mathrm{B} 3$, respectively. These findings are partly consistent with the observations of Kim et al. (2004), who found that a higher intensity of light resulted in increasing plant biomass. Moreover, higher irradiance is considered to be beneficial for vigorous root development, as a consequence of a more balanced root-to-shoot ratio and plants obtaining sufficient supplies of water or mineral nutrients for active growth (Johkan et al., 2010). However, in the present study, we found that a lower intensity of light promoted a better root growth in lettuce (RFW and RDW) than higher light intensity treatments (Table 2). Our results showed that the growthpromoting effect of light intensity on roots may be optimal when the intensity is not excessively high [such as $100 \mu \mathrm{mol} \cdot \mathrm{m}^{-2} \cdot \mathrm{s}^{-1}$ in Johkan et al. (2010)]. We also found that the WC level was lower under higher light intensity treatments, which can be attributed to a higher SDW-to-SFW ratio, higher SDW, or both. These observations revealed that a higher light intensity is beneficial for the accumulation of shoot biomass in lettuce plants.

Plant pigments can absorb light of specific wavelengths to drive photosynthesis in chloroplasts (Wang et al., 2009). For example, the action spectra of $\mathrm{Chl}$ and CAR are sensitive at $400-500$ and $630-680 \mathrm{~nm}$, respectively, whereas there is low light absorption at 530 $610 \mathrm{~nm}$ (Lin et al., 2013). With the same quality of light, higher light intensity could increase the probability that photons will be absorbed by pigments. We can see from Table 2 that although the contents of pigments (Chl $a+b$ and CAR) in terms of plant FW did not show significant difference, plants subjected to high-intensity illumination had higher total pigment contents (such as Chl $a$ and Chl $a+b$ ), as a consequence of the higher total SFW. Even with respect to pigment contents per fresh weight (FW), our experiments also revealed that $\mathrm{Chl}$ and $\mathrm{CAR}$ contents under a lower PPFD $\left(120 \mu \mathrm{mol} \cdot \mathrm{m}^{-2} \cdot \mathrm{s}^{-1}\right)$ were the lowest although the difference was not significant (A1 compared with $\mathrm{A} 3$ and $\mathrm{B} 1$ compared with B3).

Although there were no substantial differences in the photochemical contents of plants under illumination with different PPFDs, the slightly higher $\mathrm{Chl}$ and CAR contents under the higher light intensity treatments might have contributed to an increase in sugar content. The results presented in Fig. 1A indicated that lettuce plants had a higher soluble sugar content under the higher light intensity in A1 (1.94 mg. $\mathrm{g}^{-1}$ $\mathrm{FW})$ than in $\mathrm{A} 3\left(1.54 \mathrm{mg} \cdot \mathrm{g}^{-1} \mathrm{FW}\right)$, which was similar to the findings in treatments B1 (1.37 mg. $\left.{ }^{-1} \mathrm{FW}\right)$ and B3 (1.34 $\left.\mathrm{mg} \cdot \mathrm{g}^{-1} \mathrm{FW}\right)$. As photosynthesis takes place in the chloroplasts of mesophyll cells, a higher light intensity would indicate that more photons reach the surface of plant leaves and can thereby be absorbed by Chls for photosynthesis. On the other hand, as the products of photosynthesis are sugar-containing organic matter, a higher photosynthetic rate within a certain range would in turn produce more sugars under the same treatment time.

Our observations indicated that changes in the protein content of lettuce tended to vary under different intensities of light. Whereas higher protein contents were observed under higher light intensity in A1 $\left(2.74 \mathrm{mg} \cdot \mathrm{g}^{-1} \mathrm{FW}\right)$ than in A3 $\left(2.72 \mathrm{mg} \cdot \mathrm{g}^{-1}\right.$ $\mathrm{FW})$, and in $\mathrm{B} 1\left(4.48 \mathrm{mg} \cdot \mathrm{g}^{-1} \mathrm{FW}\right)$ than in $\mathrm{B} 3$ (4.42 $\left.\mathrm{mg} \cdot \mathrm{g}^{-1} \mathrm{FW}\right)$, there were no significant differences in these two pairs of treatments. Furthermore, protein contents under higher ratios of red to blue light (A1 and A3) were lower than those under higher ratios of blue to red light (B1 and B3), with plants in $\mathrm{CK}$ showing intermediate values. These observations indicated that the influence of light intensity on the accumulation of protein content is dependent on light quality. However, apart from the results obtained in B3,

Table 2. Influence of different light quantity and quality on various growth and physiological parameters of lettuce 3 weeks after transplanting.

\begin{tabular}{|c|c|c|c|c|c|c|c|}
\hline \multirow[b]{2}{*}{ Parameter } & \multicolumn{7}{|c|}{ Treatments } \\
\hline & Control & A1 & $\mathrm{A} 2$ & A3 & B1 & B2 & B3 \\
\hline$\overline{\mathrm{HP}(\mathrm{cm})}$ & $14.23 \pm 0.15 \mathrm{~d}^{\mathrm{z}}$ & $15.10 \pm 0.10 \mathrm{~b}$ & $17.10 \pm 0.10 \mathrm{a}$ & $14.47 \pm 0.06 \mathrm{c}$ & $14.10 \pm 0.10 \mathrm{~d}$ & $14.43 \pm 0.06 \mathrm{c}$ & $8.67 \pm 0.06 \mathrm{e}$ \\
\hline $\mathrm{SD}(\mathrm{mm})$ & $6.78 \pm 0.04 \mathrm{c}$ & $7.36 \pm 0.01 \mathrm{~b}$ & $7.79 \pm 0.11 \mathrm{a}$ & $7.34 \pm 0.04 \mathrm{~b}$ & $6.80 \pm 0.05 \mathrm{c}$ & $6.67 \pm 0.08 \mathrm{~d}$ & $6.09 \pm 0.01 \mathrm{e}$ \\
\hline $\mathrm{SFW}(\mathrm{g})$ & $29.46 \pm 0.35 \mathrm{~d}$ & $42.60 \pm 0.01 \mathrm{~b}$ & $51.77 \pm 1.52 \mathrm{a}$ & $35.99 \pm 0.47 \mathrm{c}$ & $21.17 \pm 0.98 \mathrm{e}$ & $36.69 \pm 0.48 \mathrm{c}$ & $15.90 \pm 0.01 \mathrm{f}$ \\
\hline SDW (g) & $1.89 \pm 0.06 \mathrm{e}$ & $3.74 \pm 0.06 \mathrm{a}$ & $2.24 \pm 0.05 \mathrm{~d}$ & $2.74 \pm 0.08 \mathrm{~b}$ & $2.39 \pm 0.07 \mathrm{c}$ & $2.36 \pm 0.03 \mathrm{c}$ & $1.23 \pm 0.01 \mathrm{f}$ \\
\hline RFW (g) & $6.01 \pm 0.04 \mathrm{~d}$ & $5.19 \pm 0.03 \mathrm{e}$ & $7.52 \pm 0.01 \mathrm{a}$ & $6.45 \pm 0.01 \mathrm{~b}$ & $3.81 \pm 0.01 \mathrm{f}$ & $6.30 \pm 0.01 \mathrm{c}$ & $5.20 \pm 0.01 \mathrm{e}$ \\
\hline RDW (g) & $0.35 \pm 0.03 b$ & $0.28 \pm 0.01 \mathrm{~d}$ & $0.38 \pm 0.01 \mathrm{a}$ & $0.31 \pm 0.01 \mathrm{c}$ & $0.21 \pm 0.01 \mathrm{f}$ & $0.32 \pm 0.01 \mathrm{c}$ & $0.25 \pm 0.01 \mathrm{e}$ \\
\hline $\mathrm{WC} /(\%)$ & $93.59 \pm 0.17 b$ & $89.03 \pm 0.25 \mathrm{~d}$ & $95.76 \pm 0.09 \mathrm{a}$ & $93.42 \pm 0.02 b$ & $88.87 \pm 0.03 \mathrm{~d}$ & $93.64 \pm 0.11 \mathrm{~b}$ & $92.26 \pm 0.03 \mathrm{c}$ \\
\hline $\mathrm{HL} /(\mathrm{cm})$ & $1.73 \pm 0.15 \mathrm{bc}$ & $1.83 \pm 0.06 \mathrm{~b}$ & $2.23 \pm 0.06 \mathrm{a}$ & $1.53 \pm 0.06 \mathrm{~d}$ & $1.35 \pm 0.05 \mathrm{e}$ & $1.63 \pm 0.06 \mathrm{~cd}$ & $1.33 \pm 0.06 \mathrm{e}$ \\
\hline $\mathrm{Chl} a /\left(\mathrm{mg} \cdot \mathrm{g}^{-1} \mathrm{FW}\right)$ & $0.72 \pm 0.02 \mathrm{a}$ & $0.64 \pm 0.16 \mathrm{ab}$ & $0.60 \pm 0.02 b$ & $0.61 \pm 0.06 \mathrm{ab}$ & $0.65 \pm 0.07 \mathrm{ab}$ & $0.66 \pm 0.02 \mathrm{ab}$ & $0.63 \pm 0.03 \mathrm{ab}$ \\
\hline $\mathrm{Chl} b /\left(\mathrm{mg} \cdot \mathrm{g}^{-1} \mathrm{FW}\right)$ & $0.05 \pm 0.01 \mathrm{a}$ & $0.04 \pm 0.02 \mathrm{~b}$ & $0.04 \pm 0.01 \mathrm{ab}$ & $0.04 \pm 0.01 \mathrm{ab}$ & $0.04 \pm 0.01 \mathrm{ab}$ & $0.04 \pm 0.01 \mathrm{ab}$ & $0.03 \pm 0.01 \mathrm{~b}$ \\
\hline Chl $a / b$ & $13.88 \pm 1.21 \mathrm{~b}$ & $17.14 \pm 2.79 b$ & $16.01 \pm 1.60 \mathrm{~b}$ & $16.87 \pm 3.78 b$ & $16.51 \pm 2.94 \mathrm{~b}$ & $15.10 \pm 1.37 \mathrm{~b}$ & $22.63 \pm 1.76 \mathrm{a}$ \\
\hline $\mathrm{Chl} a+b /\left(\mathrm{mg} \cdot \mathrm{g}^{-1} \mathrm{FW}\right)$ & $0.77 \pm 0.02 \mathrm{a}$ & $0.68 \pm 0.17 \mathrm{a}$ & $0.64 \pm 0.02 \mathrm{a}$ & $0.65 \pm 0.06 \mathrm{a}$ & $0.69 \pm 0.09 \mathrm{a}$ & $0.69 \pm 0.03 \mathrm{a}$ & $0.66 \pm 0.03 \mathrm{a}$ \\
\hline $\mathrm{CAR} /\left(\mathrm{mg} \cdot \mathrm{g}^{-1} \mathrm{FW}\right)$ & $0.10 \pm 0.01 \mathrm{a}$ & $0.10 \pm 0.03 \mathrm{a}$ & $0.10 \pm 0.01 \mathrm{a}$ & $0.10 \pm 0.01 \mathrm{a}$ & $0.10 \pm 0.01 \mathrm{a}$ & $0.11 \pm 0.01 \mathrm{a}$ & $0.10 \pm 0.01 \mathrm{a}$ \\
\hline
\end{tabular}

${ }^{\mathrm{z}}$ Different letters represent a significant difference at $\alpha$ level of 0.05 .

$\mathrm{HP}=$ height of plants; $\mathrm{SD}=$ diameter of hypocotyls (stem diameter); SFW = shoot fresh weight; RFW = root fresh weight; SDW = shoot dry weight, RDW = root dry weight; $\mathrm{HL}=$ hypocotyl length; $\mathrm{WC}=$ the water content in aerial part; $\mathrm{Chl}=$ chlorophyll; $\mathrm{Chl} a / b=\mathrm{Chl} a, \mathrm{Chl} b ; \mathrm{CAR}=$ carotenoid data were recorded 3 weeks after transplantation. 

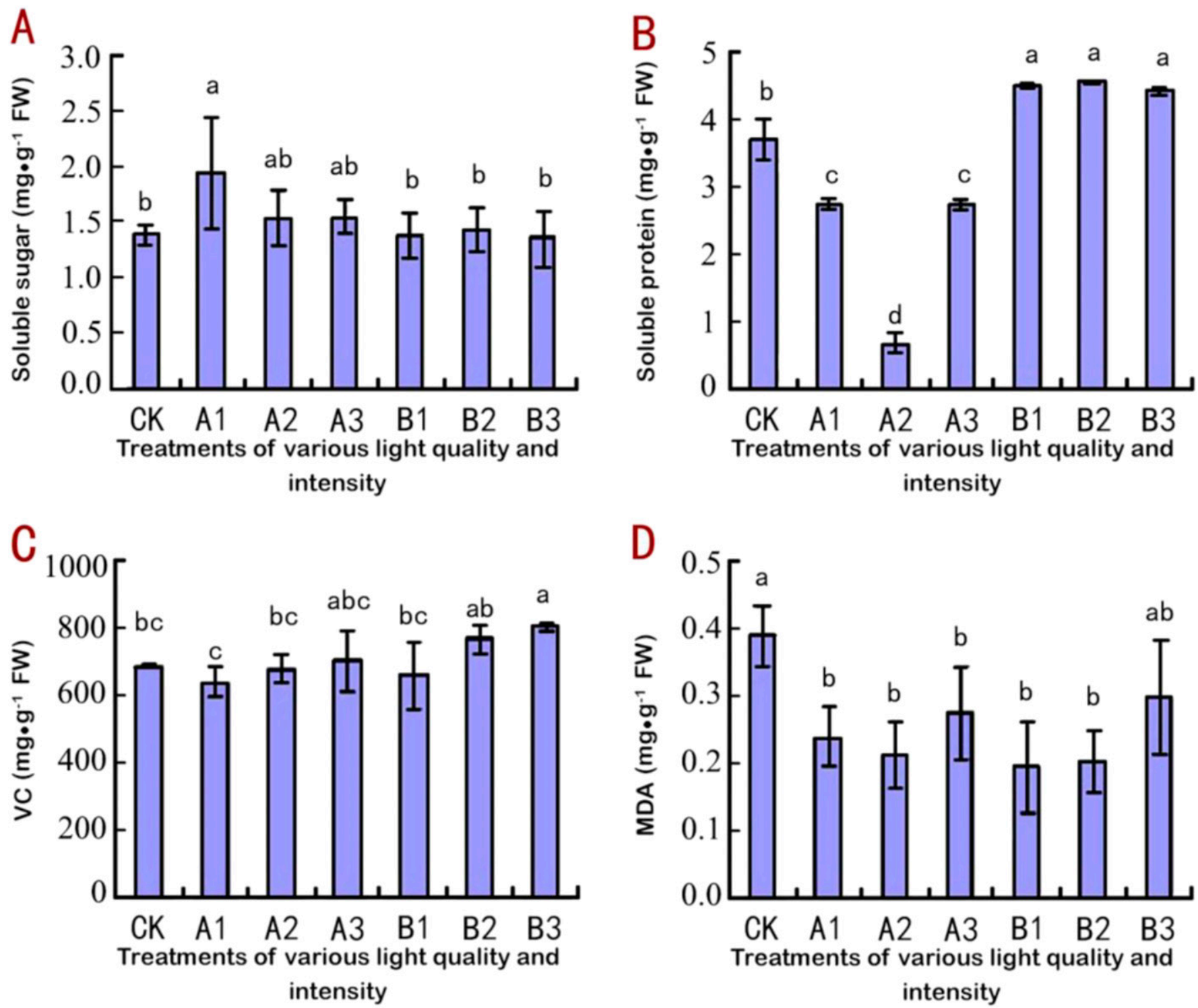

Fig. 1. Effects of different combinations of light qualities on the content of soluble sugar, soluble proteins, vitamin C (VC), and malondialdehyde (MDA) in lettuce. (A) The soluble sugar content in lettuce under treatments A1, A2, A3, B1, B2, and B3, and control (CK) on the 21 st d. (B) The soluble protein content in lettuce under treatments A1, A2, A3, B1, B2, and B3, and CK on the 21st d. (C) The VC content in lettuce under treatments A1, A2, A3, B1, B2, and B3, and CK on the 21 st d. (D) The MDA content in lettuce under treatments CK, A1, A2, A3, B1, B2, and B3, and CK on the 21st d. Values were the means of three replications with standard errors shown by vertical bars. Different letters indicate significant differences using the least significant difference's multiple range test $(\alpha$ level of $0.05, n=3)$.

there were generally no significant differences observed in the amount of vitamin $\mathrm{C}$ among the other treatments. This suggested that the light intensities set in our studies might not have had a detectable influence on vitamin $\mathrm{C}$ synthesis, and accordingly, the content of this vitamin might not be a suitable parameter to assess the nutritional quality of lettuce plants. Moreover, a decrease in the MDA content is certainly important for preventing damage to membrane systems under higher light intensity. The results shown in Fig. 1D revealed that the MDA content in lettuce was higher in treatment $\mathrm{A} 3$ than in $\mathrm{A} 1$ and higher in $\mathrm{B} 3$ than in $\mathrm{B} 1$, which indicated that the lipid membranes in plants under treatments A3 and B3 were oxidized to a certain degree. This may have a negative impact on plant growth and pigment synthesis.
Influence of different ratios of red to blue light on the biomass and biochemical contents of lettuce. Abnormal plant morphology and reduced photosynthetic rate were observed when lettuce was exposed to red LED light alone (Goins et al., 1998; Wang et al., 2009). In a further study, blue LED alone was found to reduce the photosynthetic rate of purple cabbage (Ziwei) (Yang et al., 2016). This suggested that monochromatic red or blue light would not meet the requirements for healthy plant growth. Yorio et al. (2001) observed higher dry weight accumulation when lettuce plants grew under red light in combination with blue light compared with those plants illuminated by red light alone. In our experiments, treatments $\mathrm{A} 1$ and $\mathrm{B} 1$ and treatments $\mathrm{A} 3$ and $\mathrm{B} 3$ had the same light intensity but different light qualities. By comparing these two pairs of treatments, we found that biomass parameters were higher under the treatments with a higher portion of red light (A1 and $\mathrm{A} 3$ ) compared with $\mathrm{B} 1$ and $\mathrm{B} 3$, respectively, under the same PPFD. By contrast, the results of our comparisons between treatments $\mathrm{A} 1$ and $\mathrm{B} 1$ and treatments A3 and B3 showed that irradiation with a higher portion of blue LED light suppressed the leaf growth of lettuce seedlings. On the 21 st $\mathrm{d}$ of treatment, all the biomass parameters examined were better in lettuce treated with blue + red LED lights with a higher portion of red light than in those treated with blue + red LED lights with a higher portion of blue light. In a similar study, Ohashi-Kaneko et al. (2007) observed a decrease in SDW under the illumination of $75 \%$ blue light in combination with red, far-red, green, and 
ultraviolet light, which indicated that the blue spectrum does not contribute substantially to the accumulation of plant biomass. Therefore, to enhance lettuce yield, a higher ratio of red to blue light might be a better option. However, the optimal ratio of red to blue light would probably depend on both the lettuce cultivar and the intensity of light.

The absolute quantity of red light was the highest in treatment A1 $\left(105 \mu \mathrm{mol} \cdot \mathrm{m}^{-2} \cdot \mathrm{s}^{-1}\right)$, followed by A3 $\left(84 \mu \mathrm{mol} \cdot \mathrm{m}^{-2} \cdot \mathrm{s}^{-1}\right)$ and B1 (45 $\left.\mu \mathrm{mol} \cdot \mathrm{m}^{-2} \cdot \mathrm{s}^{-1}\right)$, and the lowest in B3 (36 $\mu \mathrm{mol} \cdot \mathrm{m}^{-2} \cdot \mathrm{s}^{-1}$, which was consistent with the order of the HP, SD, HL, and shoot weight of lettuce subjected to red + blue light treatments. Treatments with a higher portion of red light resulted in a higher SFW and SDW. In this regard, it has been reported that the optimal ratio of red to blue light differs for different plants. For example, that for rapeseed (Brassica napus L.) plantlets in vitro was $1 / 3$ ( $\mathrm{Li}$ et al., 2013), whereas that for cucumber seedlings was nine (Hernández and Kubota, 2016). These results accordingly indicated that the response of plants to light quality might be species related, cultivar related, or both.

With regard to the biochemical content of lettuce, we found that plants treated with red + blue LED light with a lower portion of red light (B3) had a higher $\mathrm{Chl} a / b$ ratio than lettuce seedlings treated with light containing a higher portion of red light (A1 and A3). Evans and Poorter (2001) have similarly reported an increase in the $\mathrm{Chl} a / b$ ratio when plants were irradiated with an increased portion of blue light. However, we found that although the portion of blue light was the highest in the B1 treatment, the ratio of Chl $a / b$ in this treatment was lower than that in either treatment A1 or A3. This observation tended to indicate that an increase in the $\mathrm{Chl}$ $a / b$ ratio of lettuce due to a higher portion of blue light might occur only within a certain range.

Light quality also plays a significant regulatory role in protein metabolism. For example, it has previously been demonstrated that more soluble protein accumulates in leaves and seeds when plants grew under blue light (Kowallik, 1982). Blue light can promote the expression of antioxidant enzymes and reduce the deprivation of soluble proteins in plants (Shin et al., 2008; Wang et al., 2009). Moreover, blue light is believed to promote dark respiration in the mitochondria of plants, which in turn stimulates protein synthesis (Kowallik, 1982). The results of the present study indicated that the relationship between protein content and light intensity depends on the ratio of blue to red light. Figure 1B showed that the lettuce illuminated with light containing a higher component of blue light (B1 with 105 $\mu \mathrm{mol} \cdot \mathrm{m}^{-2} \cdot \mathrm{s}^{-1}$ and B3 with $84 \mu \mathrm{mol} \cdot \mathrm{m}^{-2} \cdot \mathrm{s}^{-1}$ ) exhibited higher protein content than that illuminated with a lower component of blue light (A1 with $45 \mu \mathrm{mol} \cdot \mathrm{m}^{-2} \cdot \mathrm{s}^{-1}$ and A3 with $\left.36 \mu \mathrm{mol} \cdot \mathrm{m}^{-2} \cdot \mathrm{s}^{-1}\right)$. This may have been attributable to the enhanced respiration that could provide energy for the synthesis of amino acids and proteins and assimilation of carbon under blue light. As the photon energy of blue light is relatively high, this could also indicate that the synthesis of proteins may be related to a need for higher photon energy. However, our studies indicated that with an increase in the portion of blue light, the increase in protein content became increasingly nonsignificant. These observations also indicated that, similar to the $\mathrm{Chl} a / b$ ratio, an increase in protein content in response to an increase in the portion of blue light might occur only within a certain range. Poorter et al. (2010) have demonstrated the value of dose-response curves for quantitative investigation of environmental effects on plant phenotypes, which facilitated a better understanding of plant-environment interactions than the assessment of two treatments only. Nevertheless, it is still not clear whether the enhanced effect of blue light on leaf photosynthetic capacity is a qualitative threshold response or a quantitative progressive response, or a combination of both. We suggested that, within a certain range, to increase the $\mathrm{Chl} a / b$ ratio and protein content in lettuce, treatment with LED lights containing a higher portion of blue wavelengths would enhance photosynthetic ability after transplantation.

Effect of green light. The green LED light used in this study was to replace some portions of red and blue lights. When comparing treatment A1 with A2 and treatment B1 with B2, which had the same PPFD level but differed in that the latter two treatments contained $20 \%$ green light, lettuce showed distinct growth responses to the same irradiance level. Lettuce plants treated with the green-containing LED light showed higher biomass production than those illuminated with red and blue only or the fluorescent light under the same light intensity. In another study, Kim et al. (2004) observed increased shoot growth in lettuce illuminated with cool-white fluorescent light compared with green fluorescent light under the same PPFD. Their report indicated that a high percentage of green light in the light source suppresses plant growth. However, in our study, the shoots and roots of lettuce illuminated with light containing $30 \mu \mathrm{mol} \cdot \mathrm{m}^{-2} \cdot \mathrm{s}^{-1}$ green light showed higher biomass content than those of lettuce illuminated without green light and CK. The most rapid growth rate was recorded for the lettuce illuminated with red and blue LEDs containing 20\% green light (RGB).

In contrast to our observations, it has previously been observed that lower amount of green light (e.g., 5\%) has a negligible influence on plant growth and photosynthesis (Kim et al., 2004) because green light is less effective in promoting photosynthesis than either red or blue light (McCree, 1972). Moreover, it was found that higher levels of supplemental green light decrease plant growth rate (Kim et al., 2004). These findings indicated that light sources with a high fraction of green photons $(>50 \%)$ are not only energetically uneconomical compared with low green light sources but are also unfavorable to plant growth (Kim et al., 2004). Nevertheless, comparisons between treatments $\mathrm{A} 2$ and $\mathrm{A} 3$ and treatments $\mathrm{B} 2$ and B3, in which the latter two treatments were obtained by removing green light from the former two, indicated that the growth and physiological parameters of lettuce showed a decreasing trend after the green light had been removed. Kim et al. (2004) have reported similar results for the lettuce 'Waldmann's Green' when plants were grown under red and blue lights and red, blue, and green LEDs (containing 24\% green light). Our experiments demonstrated that the addition of $20 \%$ or a slightly higher percentage of green light to red and blue LEDs enhanced lettuce growth compared with plants grown under FLs or a combination of red and blue lights only. Therefore, the addition of an appropriate amount of green light might be beneficial in stimulating the growth and development of lettuce plants.

To be effective, light must be intercepted and absorbed by photosynthetic tissues. Green light is often considered to be insignificant in driving photosynthesis, mainly because of the low absorbance in the absorption spectra of purified Chls (Sun et al., 1998). Compared with $\approx 90 \%$ of red or blue light absorbed by plant leaf pigments, some $70 \%$ to $80 \%$ of green light is absorbed (Ichiro et al., 2009). The absorption of green wavelengths by the photosynthetic apparatus is also considered to be very low (Salisbury and Ross, 1985). However, in our study, we observed differences in these pigments and some other biochemical contents, such as soluble sugars and vitamin $\mathrm{C}$ content, in lettuce illuminated by light with or without green light, although these differences were not significant (comparing the results in A2 with $\mathrm{A} 3$ and $\mathrm{B} 2$ with $\mathrm{B} 3$ ). These observations could be attributable to the fact that the addition of green light to the combination of red and blue LEDs promotes plant growth because green light can penetrate the plant canopy more efficiently than either red or blue light (Klein, 1992). Leaves in the lower canopy would, thus, be able to use the transmitted green light for photosynthesis (Kim et al., 2004). McCree (1970) also found that the response spectra for photosynthesis indicated that green light is in an active spectral region in higher plants. It is, thus, conceivable that green light is absorbed by auxiliary pigments and that the absorbed energy is transferred to the photosynthetic reaction center. These studies showed that green light has an influence on both the morphological and biochemical properties of lettuce plants.

\section{Conclusion}

In this study, we investigated the effects of light quality and intensity on the biomass and contents of physiological and biochemical compounds of hydroponically grown lettuce. Biomass and PH, SD, SFW, and $\mathrm{WC}$ in the aerial parts were optimal in 
plants illuminated with RGB (6:2:2) LED light at $150 \mu \mathrm{mol} \cdot \mathrm{m}^{-2} \cdot \mathrm{s}^{-1}$ PPFD. Illumination combining a higher portion of red light and higher intensity [RB (7:3) at 150 $\left.\mu \mathrm{mol} \cdot \mathrm{m}^{-2} \cdot \mathrm{s}^{-1} \mathrm{PPFD}\right]$ was proven to be the best for enhancing soluble sugar content, whereas soluble protein and vitamin $\mathrm{C}$ contents were higher in plants illuminated with a higher portion of blue light. Furthermore, replacement of an appropriate amount of red light, blue light, or both with green light from combinations of red and blue light was found to be conducive to a more balanced growth of plants, which resulted in a healthier growth and a better quality of lettuce compared with those plants grown under blue light, red light, or both. These findings indicated that green light can sometimes be effective in promoting plant growth and improving plant quality. Using LEDs has a positive effect on plant growth and the accumulation of functional chemicals in lettuce compared with fluorescent light under the same PPFD. We also found that for different cultivation purposes, such as aiming at higher yield or better quality, different combinations of lights should be used. Thus, based on our findings, it can be concluded that when the goal of cultivation is to obtain plants with higher quality, it is essential to select an appropriate combination of light quality, intensity, or both, which will also affect the morphological growth of plants.

\section{Literature Cited}

Arnon, D.I. 1949. Copper enzymes in isolated chloroplasts: Polyphenol oxidase in Beta vulgaris. Plant Physiol. 24:1-15.

Baroli, I., G.D. Price, M.R. Badger, and S.V. Caemmerer. 2008. The contribution of photosynthesis to the red light response of stomatal conductance. Plant Physiol. 146:737-747.

Bradford, M.M. 1976. A rapid and sensitive method for quantitation of microgram quantities of protein utilizing the principle of proteindye binding. Anal. Biochem. 72:248-254.

Briggs, W.R. and J.M. Christie. 2002. Phototropins 1 and 2: Versatile plant blue-light receptors. Trends Plant Sci. 7:204-210.

Chory, J. and D. Wu. 2001. Weaving the complex web of signal transduction. Plant Physiol. 125:77-80.

Dougher, T.A.O. and B. Bugbee. 2001. Differences in the responses of wheat, soybean, and lettuce to reduced blue radiation. Photochem. Photobiol. 73:199-207.

Du, Z.Y. and W.J. Bramlage. 1992. Modified thiobarbituric acid assay for measuring lipid oxidation in sugar-rich plant tissue extracts. J. Agr. Food Chem. 40:1566-1570.

Evans, J.R. and H. Poorter. 2001. Photosynthetic acclimation of plants to growth irradiance: The relative importance of specific leaf area and nitrogen partitioning in maximizing carbon gain. Plant Cell Environ. 24:755-767.

Fu, W., P. Li, Y. Wu, and J. Tang. 2012. Effects of different light intensities on anti-oxidative enzyme activity, quality and biomass in lettuce. HortScience 39:129-134.

Goins, G.D., N.C. Yorio, M.M. Sanwo-Lewandowski, and C.S. Brown. 1998. Life cycle experiments with Arabidopsis grown under red light-emitting diodes (LEDs). Life Support Biosph. Sci. 5:143-149.
Gruszecki, W.I., R. Luchowski, M. Zubik, W. Grudzinski, E. Janik, M. Gospodarek, J. Goc, Z. Gryczynski, and I. Gryczynsk. 2010. Bluelight-controlled photoprotection in plants at the level of the photosynthetic antenna complex LHCII. J. Plant Physiol. 167:69-73.

Heo, J., C. Lee, D. Chakrabarty, and K. Paek. 2002. Growth responses of marigold and salvia bedding plants as affected by monochromic or mixture radiation provided by a LightEmitting Diode (LED). Plant Growth Regulat. 38:225-230.

Hernández, R. and C. Kubota. 2016. Physiological responses of cucumber seedlings under different blue and red photon flux ratios using LEDs. Environ. Expt. Bot. 121:66-74.

Huan, L.V.T. and M. Tanaka. 2004. Effects of red and blue light-emitting diodes on callus induction, callus proliferation, and protocormlike body formation from callus in Cymbidium Orchid. Environ. Control Biol. 42:57-64.

Huh, K.Y., J.H. Choi, K.S. Kim, and K.Y. Huh. 1997. Effects of light quality on growth and flowering of Hibiscus syriacus L. J. Korean Soc. Hort. Sci. 38:272-277.

Ichiro, T., F. Takashi, I. Takeshi, C. Wah Soon, and O. Riichi. 2009. Green light drives leaf photosynthesis more efficiently than red light in strong white light: Revisiting the enigmatic question of why leaves are green. Plant Cell Physiol. 50:684-697.

Jeong, S.W., S. Park, J.S. Jin, O.N. Seo, G.S. Kim, Y.H. Kim, H. Bae, G. Lee, S.T. Kim, W.S. Lee, and S.C. Shin. 2012. Influences of four different light-emitting diode lights on flowering and polyphenol variations in the leaves of Chrysanthemum (Chrysanthemum morifolium). J. Agr. Food Chem. 60:9793-9800.

Johkan, M., K. Shoji, F. Goto, S. Hashida, and T. Yoshihara. 2010. Blue light-emitting diode light irradiation of seedlings improves seedling quality and growth after transplanting in red leaf lettuce. HortScience 45:1809-1814.

Kang, J. H., S. KrishnaKumar, S.L.S. Atulba, B.R. Jeong, and S.J. Hwang. 2013. Light intensity and photoperiod influence the growth and development of hydroponically grown leaf lettuce in a closed-type plant factory system. Hort. Environ. Biotechnol. 54:501-509.

Kim, H.H., G.D. Goins, R.M. Wheeler, and J.C. Sager. 2004. Green-light supplementation for enhanced lettuce growth under red- and blue-light-emitting diodes. HortScience 39: 1617-1622.

Klein, R.M. 1992. Effects of green light on biological systems. Biol. Rev. Camb. Philos. Soc. 67:199-284

Klein, R.M., P.C. Edsall, and A.C. Gentile. 1965. Effects of near ultraviolet and green radiations on plant growth. Plant Physiol. 40:903906.

Kobayashi, K., T. Amore, and M. Lazaro. 2013. Light-emitting diodes (LEDs) for miniature hydroponic lettuce. Opt. Photonics J. 03:74-77.

Kopsell, D.A. and D.E. Kopsell. 2008. Genetic and environmental factors affecting plant lutein/ zeaxanthin. Agro Food Ind. Hi-Tech 19:44-46.

Kowallik, W. 1982. Blue light effects on respiration. Annu. Rev. Plant Physiol. 33:51-72.

Lee, J.H., P. Felipe, Y.H. Yang, M.Y. Kim, O.Y. Kwon, D.E. Sok, H.C. Kim, and M.R. Kim. 2009. Effects of dietary supplementation with red-pigmented leafy lettuce (Lactuca sativa) on lipid profiles and antioxidant status in C57BL/ $6 \mathrm{~J}$ mice fed a high-fat high-cholesterol diet. Brit. J. Nutr. 101:1246-1254.

Li, Q. and C. Kubota. 2009. Effects of supplemental light quality on growth and phytochemicals of baby leaf lettuce. Environ. Expt. Bot. 67:5964.

Li, H., C. Tang, and Z. Xu. 2013. The effects of different light qualities on rapeseed (Brassica napus L.) plantlet growth and morphogenesis in vitro. Scientia Hort. 150:117-124.

Lin, K.H., M.Y. Huang, W.D. Huang, M.H. Hsu, Z.W. Yang, and C.M. Yang. 2013. The effects of red, blue, and white light-emitting diodes on the growth, development, and edible quality of hydroponically grown lettuce (Lactuca sativa L. var. capitata). Scientia Hort. 150:86-91.

Liu, L., L. Wang, F. Deng, Y. Huang, D.Y. Liu, W.J. Ren, and W.Y. Yang. 2013. Response of different rice genotypes to osmotic regulation substance content and protective enzyme activities in leaves under shading. Rice Sci. 20:276-283.

McCree, K.J. 1970. The action spectrum, absorptance and quantum yield of photosynthesis in crop plants. Agr. Meteorol. 9:191-216.

McCree, K.J. 1972. Test of current definitions of photosynthetically active radiation against leaf photosynthesis data. Agr. Meteorol. 10:443453.

Nicolle, C., C. Nicolas, G. Elyett, J. Lydia, R. Edmond, M. Andrzej, A. Pierre, and R. Christian. 2004. Health effect of vegetable-based diet: Lettuce consumption improves cholesterol metabolism and antioxidant status in the rat. Clin. Nutr. 23:605-614.

Ohashi-Kaneko, K., M. Takase, N. Kon, K. Fujiwara, and K. Kurata. 2007. Effect of light quality on growth and vegetable quality in leaf lettuce, spinach and komatsuna. Environ. Control Biol. 45:189-198.

Park, C.H., O.Y. Kwon, H.J. Shim, M.H. Kim, J.H. Lee, K.J. Lee, X.W. Liu, D.E. Sok, and M.R. Kim. 2008. Protection of green leafy vegetable extracts against oxidation of human low density lipoprotein. Food Sci. Bio. 17:151-155.

Pérez-Balibrea, S., D.A. Moreno, and G.V. Cristina. 2008. Influence of light on health-promoting phytochemicals of broccoli sprouts. J. Sci. Food Agr. 88:904-910.

Poorter, H., U. Niinemets, A. Walter, F. Fiorani, and U. Schurr. 2010. A method to construct dose-response curves for a wide range of environmental factors and plant traits by means of a meta-analysis of phenotypic data. J. Expt. Bot. 61:2043-2055.

Salisbury, F.B. and C.W. Ross. 1985. Plant physiology. Wadsworth, Belmont, CA.

Shin, K.S., H.N. Murthy, J.W. Heo, E.J. Hahn, and K.Y. Paek. 2008. The effect of light quality on the growth and development of in vitro cultured Doritaenopsis plants. Acta Physiol. Plant. 30:339-343.

Son, K.H. and M.M. Oh. 2013. Leaf shape, growth, and antioxidant phenolic compounds of two lettuce cultivars grown under various combinations of blue and red light-emitting diodes. HortScience 48:988-995.

Song, W.S., H.S. Park, and J.H. Lee. 1997. Effect of light quality on the growth of Hibiscus syriacus L. Res. Rpt. For. Gen. Res. Inst. Korea 33:104-111.

Sun, J., J.N. Nishio, and T.C. Vogelmann. 1998. Green light drives $\mathrm{CO}_{2}$ fixation deep within leaves. Plant Cell Physiol. 39:1020-1026.

Wang, X. K. 2006. Principles and techniques of plant physiological biochemical experiment, $\mathrm{p}$. 190-192. Higher Educ. Press, Beijing, China (in Chinese).

Wang, H., M. Gu, J.X. Cui, K. Shi, Y.H. Zhou, and J.Q. Yu. 2009. Effects of light quality on $\mathrm{CO}_{2}$ assimilation, chlorophyll-fluorescence quenching, expression of Calvin cycle genes and 
carbohydrate accumulation in Cucumis sativus. J. Photochem. Photobiol. B 96:30-37.

Wettstein, D.V. 1957. Chlorophyll-letale und der submikroskopische formwechsel der plastiden. Expt. Cell Res. 12:427-506.

Wu, M.C., C.Y. Hou, C.M. Jiang, Y.T. Wang, C.Y Wang, H.H. Chen, and H.M. Chang. 2007. A novel approach of LED light radiation improves the antioxidant activity of pea seedlings. Food Chem. 101:1753-1758.

Yang, B., X. Zhou, R. Xu, J. Wang, Y. Lin, J. Pang, S. Wu, and F. Zhong. 2016. Comprehensive analysis of photosynthetic characteristics and quality improvement of purple cabbage under different combinations of monochromatic light. Front. Plant Sci. 7:1788.
Yorio, N.C., G.D. Goins, H.R. Kagie, R.M. Wheeler, and J.C. Sager. 2001. Improving spinach, radish, and lettuce growth under red light-emitting diodes (LEDs) with blue light supplementation. HortScience 36:380-383.

Zao, X., B.S. Kyung, and R.K. Mee. 2004. Antioxidant activity of salad vegetables grown in Korea. J. Food Sci. Nutr. 9:289-294. 